УДК 541.127

\title{
АНТИОКСИДАНТНОЕ И ПРООКСИДАНТНОЕ ДЕЙСТВИЕ АСКОРБИНОВОЙ КИслОтЫ
}

\author{
() Р.Л. Варданян ${ }^{1}$, Л.Р. Варданян ${ }^{1}$, С.А. Айрапетян ${ }^{1}$, Л.Р. Арутюнян ${ }^{2}$, Р.С. Арутюнян ${ }^{2}$ \\ ${ }^{1}$ Горисский государственный университет, Авангард, 4, Горис (Армения), \\ e-mail:vrazmik@rambler.ru \\ ${ }^{2}$ Ереванский государственный университет, ул. Алека Манукяна, 1, Ереван \\ 0025 (Армения), e-mail: syuzanhayrapetyan@rambler.ru
}

Исследовано антиоксидантное действие аскорбиновой кислоты (АК) на процесс инициированного окисления кумола. Установлено, что антиоксидантное действие АК проявляет при сравнительно низких концентрациях ([AK] $\leq 9,77 \cdot 10^{-3}$ моль/л). Определено число радикалов, обрывающихся на одной молекуле АК ( $f$-антиоксидантная емкость). Показано, что $f<0,6$, при концентрациях АK $>1 \cdot 10^{-2}$ моль/л периоды индукции на кинетических кривых поглощения кислорода исчезают. Изучены закономерности автоокисления АК в растворах ДМСО, ДМСО+вода, ДМСО+хлорбензол. Показано, что больше, вода подавляет скорость автоокисления АК, а хлорбензол, наоборот, в 1,14 раза увеличивает скорость по сравнению с ДМСО. Установлено, что скорость автоокисления АК в ДМСО описывается уравнением $V=k[A K] \sqrt{O_{2}}$, где $k=1,14 \cdot 10^{3} \exp (-9440 / R T)$.

Ключевые слова: аскорбиновая кислота, антиоксидантное и прооксидантное свойство, антиоксидантная емкость, автоокисление, сольватация.

\section{Введение}

В литературе часто упоминается о том [1-4], что аскорбиновая кислота (АК) - витамин С является мощным антиоксидантом, благодаря чему регулируются окислительно-восстановительные процессы в организме, тем самым предотвращая многие заболевания радикального происхождения. Помимо этого, АК в организме восстанавливает другие антиоксиданты, такие как витамины А и Е. При ее участии уменьшается количество холестерина и обезжиривается множество токсичных соединений, она принимает активное участие в защите липидов от перекисного окисления [5-7]. АК - это уникальное полифункциональное соединение, обладающее способностью обратимо окисляться и восстанавливаться, благодаря чему она принимает участие в важнейших процессах живой клетки [8], является признанным антиоксидантом [1] и активным антидотом свободнорадикальных механизмов, протекание которых усиливается при патологических системах.

Однако, как отмечается в работе [9], высказанные Л. Полингом надежды на активацию защитных сил с помощью АК, способствующей излечению от рака, не нашли явного подтверждения. Более того, доказано, что при лучевой терапии использование АК приводит к повышенной устойчивости опухолевых

Варданян Размик Левонович - доктор химических наук, професcop, e-mail: vrazmik@rambler.ru Варданян Луиза Размиковна - доцент, кандидат химических наук, e-mail: luisemari@ rambler.ru Айрапетян Сюзанна Арсеновна - соискатель, e-mail: syuzanhayrapetyan@ rambler.ru Арутюнян Лусине Ромиковна - доцент, кандидат химических наук, e-mail: romik@ ysu.am Арутюнян Ромик Суренович - доктор химических наук, професcop, e-mail: romik@ysu.am клеток. В этих целях АК не проявляет высокой антиоксидантной-антирадикальной активности. Это, по всей вероятности, связано с тем, что АК, помимо антиоксидантного, одновременно обладает мощным прооксидантным свойством [10, 11].

Эфирные масла и экстракты из растений и их плодов содержат в достаточном количестве антиоксидантные вещества, в частности витамин С.

\footnotetext{
* Автор, с которым следует вести переписку.
} 
Например, содержание витамина С в 100 г съедобной части петрушки составляет 150 мг, черной смородины - 200 мг, шиповника - 1200 мг, перца - 180 мг, с чем и связаны их лечебные свойства. Несмотря на огромный шум вокруг витамина С как мощного антиоксиданта, в литературе редко встречаются работы, где на конкретной радикально-цепной реакции изучался бы механизм действия АК как антиоксиданта.

Цель данной работы - исследование механизма и закономерности действия АК на процесс радикально-цепного окисления углеводорода.

\section{Экспериментальная часть}

В качестве модельной реакции было выбрано инициированное азодиизобутиронитрилом (АИБН) жидкофазное окисление кумола. В качестве реакционной среды использовали диметилсульфоксид (ДМСО) и воду, в которых хорошо растворяется АК, и тем самым обеспечивается возможность изучения процесса окисления в гомофазных условиях.

За кинетикой процесса окисления следили волюметрическим методом, измеряя количество поглощенного кислорода при данной температуре и атмосферном давлении (650 мм рт. ст.) кислорода на манометрической установке, описанной в [12]. Изучение процесса выполнялось в кинетической области, где скорость реакции не зависит от скорости перемешивания реакционной смеси. По кинетическим кривым графическим методом определяли величину периода индукции путем экстраполирования прямолинейных участков кинетической кривой до их пересечения с координатом абсцисса.

В работе использовались дважды перегнанная вода, АИБН, хлорбензол, кумол, ДМСО - очищенные

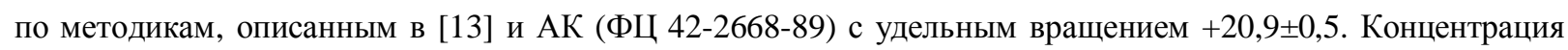
кумола во всех опытах составляла 2,87 моль/л.

\section{Результаты и их обсуждения}

На рисунке 1 представлены кинетические кривые поглощения кислорода системой АИБН - ДМСО кумол - хлорбензол, соответственно, в отсутствии и присутствии различных концентрации АК.

Из рисунка видно, что в присутствии АК на кинетических кривых появляются четко выраженные периоды индукции, что свидетельствует об антиоксидантной активности АК. Однако обнаруженные периоды индукции $\tau$ не описываются уравнением (1), характерным для классических ингибиторовантиоксидантов [4].

$$
\tau=f \cdot \frac{[I n H]_{0}}{V_{i}}
$$

где $[\operatorname{InH}]_{0}$ - исходная концентрация ингибитора, в нашем случае АК, $V_{i}$ - скорость инициирования, $f$ - стехиометрический коэффициент ингибировния - число радикалов, обрывающихся на одной молекуле ингибитора-антиоксиданта.

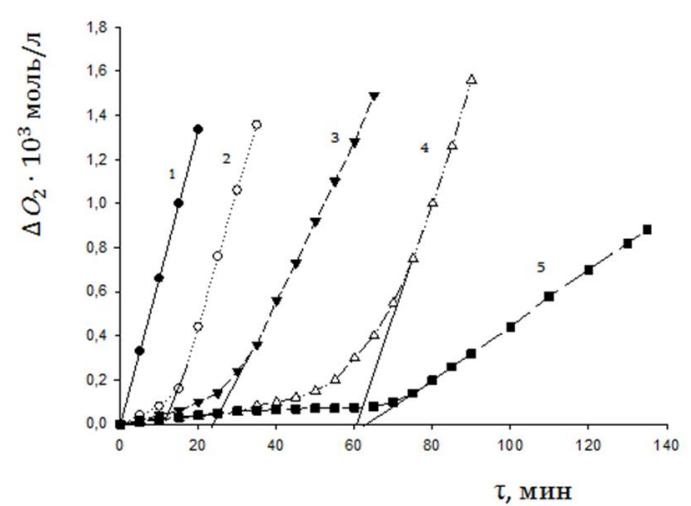

Рис. 1. Кинетические кривые поглощения кислорода в процессе окисления кумола в отсутствие 1) и в присутствии 2) $0,59 \cdot 10^{-4} ; 3$ ) $3,42 \cdot 10^{-2}$; 4) $5,625 \cdot 10^{-4}$; 5) $9,77 \cdot 10^{-3}$ моль/л АК. $V_{i}=3,435 \cdot 10^{-8}$ моль $/ л \cdot c, 328 \mathrm{~K}$

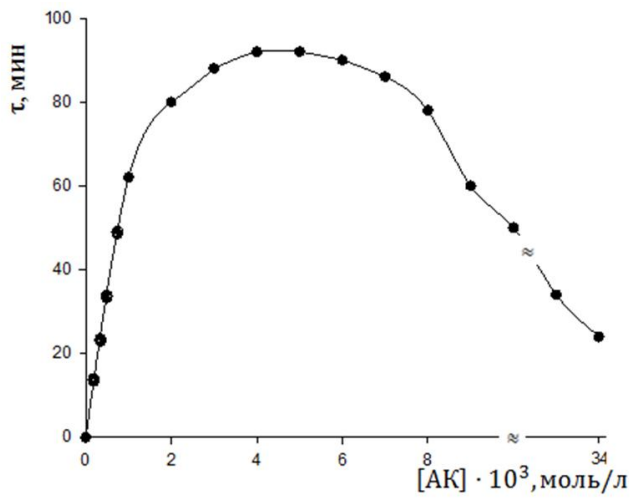

Рис. 2. Зависимость периодов индукции от концентрации АК в окисляющемся кумола. $V_{i}=0.3410^{-7} \frac{\text { моль }}{л} \cdot c, T=348 \mathrm{~K}$ 
Как следует из рисунка 3, с увеличением концентрации АК периоды индукции проходят через максимум, а при более высоких концентрациях стремятся к нулю. Пользуясь уравнением (1), для низких концентрации АК $\left(<0,56 \cdot 10^{-4}\right.$ моль/л) вычислены значения антиоксидантной емкости $(f)$. Как видно из таблицы 1 , значение $f$ получилось меньше 0,6 . Отметим, что для классических ингибиторов-фенолов $f=2$ [14].

Из таблицы 1 и рисунка 1 следует также, что скорость поглощения кислорода окисляющегося кумола после выхода из периодов индукции (при низких концентрациях АК) уменьшается с ростом концентрации АК, а начиная с $[\mathrm{AК}]>1 \cdot 10^{-2}$, наоборот, увеличивается.

Необходимо отметить, что подобные зависимости были обнаружены и в работах $[9,15]$.

Аномальные зависимости $\tau, f$ и $V_{\infty}$ от концентрации АК можно объяснить, предполагая, что АК подвергается автоокислению, что приводит к увеличению $V_{i}$ за счет реакции

$$
A K+\mathrm{O}_{2} \rightarrow A K^{\prime}+\mathrm{HO}_{2}^{\prime}
$$

либо окисляется, принимая участие в реакции продолжения цепей

$$
\begin{gathered}
A K+R O_{2}^{\prime} \rightarrow A K^{\prime}+R O O H \\
A K^{\prime}+O_{2} \rightarrow A K O_{2}^{\prime}
\end{gathered}
$$

Рис. 3. Кинетические кривые поглощения кислорода автооксиляющегося АК в ДМСО:

1) $[\mathrm{AK}]=7,55 \cdot 10^{-3}$ моль/л; 2) $[\mathrm{AK}]=2,88 \cdot 10^{-2}$ моль $/ л$;

3) $[\mathrm{AK}]=6,1 \cdot 10^{-2}$ моль/л. $328 \mathrm{~K}$

\begin{tabular}{|c|c|c|c|c|c|}
\hline $\mathrm{T},{ }^{\circ} \mathrm{C}$ & {$[A K] \cdot 10^{4}$, моль/л } & $\tau$, мин & $V_{i} \cdot 10^{7}$, моль/л $\cdot \mathrm{c}$ & $f$ & $V_{\infty} \cdot 10^{6}$, моль $/ л \cdot \mathrm{c}$ \\
\hline 328 & 0 & - & - & - & 0,90 \\
\hline 328 & 5,70 & 45 & 0,34 & 0,19 & 0,85 \\
\hline 328 & 1,18 & 25 & 0,34 & 0,44 & 1,00 \\
\hline 328 & 0,59 & 17 & 0,34 & 0,6 & 1,00 \\
\hline 328 & 2,95 & 47 & 0,17 & 0,16 & 0,81 \\
\hline 328 & 2,95 & 36 & 0,34 & 0,25 & 0,88 \\
\hline 328 & 5,625 & 60 & 0,34 & 0,2 & 0,85 \\
\hline 328 & 10,80 & 64 & 0,34 & 0,13 & 0,85 \\
\hline 328 & 37,50 & 94 & 0,34 & 0,06 & 0,29 \\
\hline 328 & 50,0 & 90 & 0,34 & 0,04 & 0,25 \\
\hline 328 & 80 & 77 & 0,34 & 0,02 & 0,23 \\
\hline 328 & 97,7 & 63 & 0,34 & 0,01 & 0,20 \\
\hline 328 & 342,0 & 25 & 0,34 & 0,0015 & 0,71 \\
\hline 339 & 6,25 & 16 & 0,78 & 0,12 & 1,9 \\
\hline 339 & 0 & - & - & - & 1,9 \\
\hline 339 & 28,97 & 36 & 0,78 & 0,06 & 1,68 \\
\hline 348 & 0 & - & - & - & 3,0 \\
\hline 348 & 84,5 & 12 & 1,25 & 0,1 & 3,1 \\
\hline 348 & 23,35 & 43 & 1,25 & 0,15 & 2,67 \\
\hline 348 & 42,70 & 31 & 1,25 & 0,05 & 2,79 \\
\hline 348 & 60,45 & 16 & 1,25 & 0,02 & 2,27 \\
\hline 348 & 85,45 & 0 & 1,25 & - & 2,85 \\
\hline
\end{tabular}

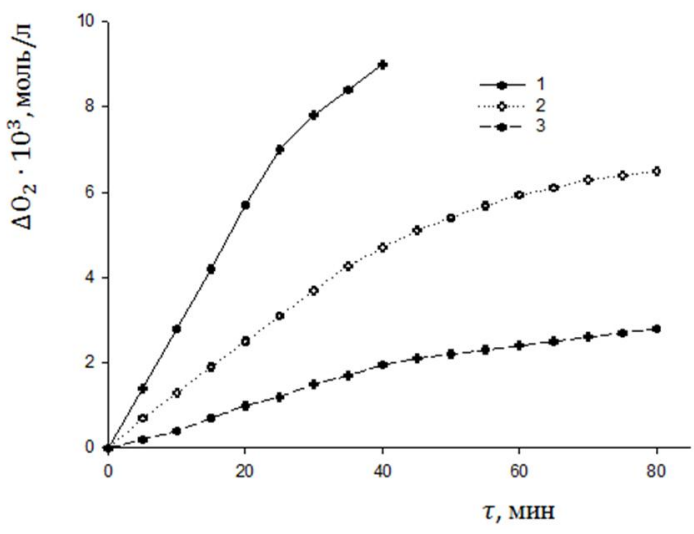

Таблица 1. Кинетические данные окисления 2,87 моль/л кумола в присутствии АК 
Для уточнения этого изучались закономерности автоокисления аскорбиновой кислоты в системах АК - ДМСО, АК - ДМСО - хлорбензол, АК - вода - ДМСО. На рисунке 3 представлены типичные кинетические кривые поглощения кислорода системой АК - ДМСО при различных концентрациях АК. Видно, что АК действительно подвергается автоокислению. Причем кинетические кривые поглощения кислорода стремятся к насыщению, т.е. скорость окисления АК во времени стремится к нулю. Обнаруженные явления нельзя объяснить антиоксидантным действием продуктов окисления АК, поскольку нами экспериментально установлено, что в присутствии полученных оксидантов, в отличие от исходной АК, инициированное окисление кумола не ингибируется. Следовательно, подобную зависимость можно объяснить тем, что часть АК в растворе ДМСО находится в сольватированном виде, к которым доступ кислорода ограничен, а окислению подвергаются только несольватированные молекулы АК

$$
A K+n D M C O \rightarrow A K(D M C O)_{n} .
$$

Во всех случаях начальные скорости окисления АК находятся в линейной зависимости от ее концентрации в первой степени и от концентрации $O_{2} 0,5$ степени (рис. 3). Подобная зависимость указывает, что автоокисление АК осуществляется по брутто реакции

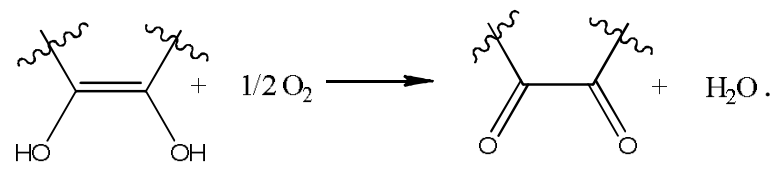

Согласно этой схеме скорость поглощения кислорода будет описываться уравнением (2)

$$
V_{O_{2}}=k[A K] \sqrt{O_{2}}
$$

где $\left[\mathrm{O}_{2}\right]$ - концентрация растворенного кислорода в ДМСО. Концентрацию растворенного кислорода определяли по формуле

$$
\left[O_{2}\right]=\alpha \gamma\left(P-P_{R H}\right)
$$

где $\alpha$ - доля $O_{2}$ в газовой фазе, $P$ - атмосферное давление, $P_{R H}$ - давление насыщенных паров растворителя (ДМСО) над раствором, $\gamma$ - коэффициент Генри, отражающий растворимость $O_{2}$ в зависимости от температуры [16].

$$
\gamma=2,45 \cdot 10^{-3} \exp (900 / R T)
$$

В условиях наших опытов $P=0,86$ атм., $P_{R H}$ принимали равным нулю. С помощью уравнения (1) и рисунка 4 определили температурную зависимость параметра окисляемости (k) АК в ДМСО. Выяснилось, что

$$
k=1,44 \cdot 10^{3} \exp (-9440 / R T) .
$$

Учитывая, что фармакологическое действие АК проявляется в живом организме, интересно было исследовать ее прооксидантное свойство в системе вода - АК - ДМСО. Результаты этих исследований приведены в таблице 2. Из результатов таблицы следует, что в системе вода - АК - ДМСО с повышением доли воды скорость окисления АК уменьшается до нуля. Следовательно, в чистой воде АК практически не

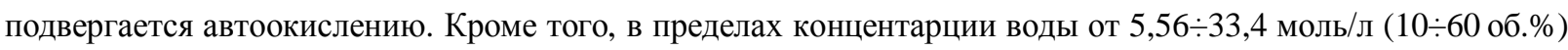
на кинетических кривых поглощения кислорода появляются периоды индукции.

Прооксидантное действие АК изучали также в системе АК - ДМСО - хлорбензол. Опыты проводились при постоянной температуре (348 К) и при различных концентрациях АК. Концентрация ДМСО во всех опытах составляла 1,404 моль/л (10 об.\%). Результаты приведены на рисунке 4 (прямая). Из рисунка 4 видно, что в системе АК - ДМСО - хлорбензол, по сравнению с системой АК - ДМСО, АК окисляется в 1,14 раза быстрее (сравнить тангенсы углов прямых (1) и (2)). Это можно обьяснить тем, что в чистом ДМСО АК больше ассоциирована, чем в смеси ДМСО - хлорбензол, т.е. концентрация свободных молекул АК в системе ДМСО+хлорбензол больше, чем в чистом ДМСО. 


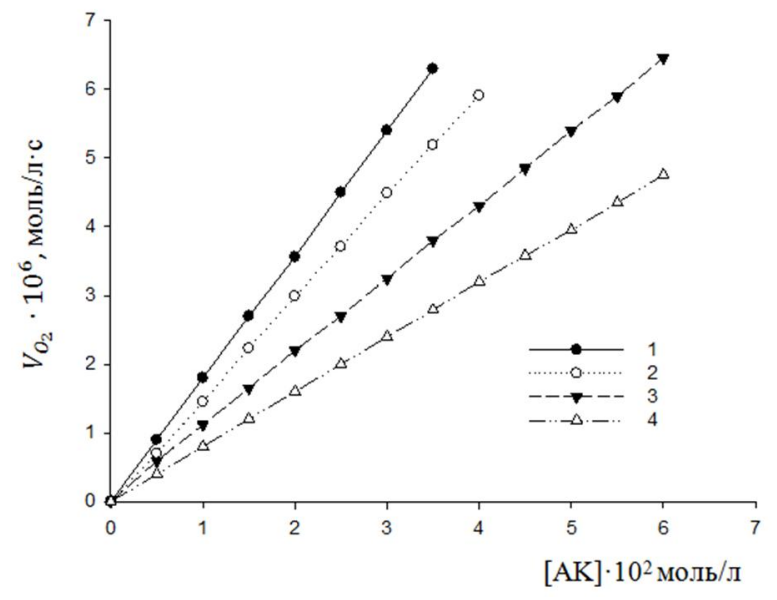

Рис. 4. Зависимость скорости автоокисления АК от ее концентрации 4) 328К, 3) 339К, 1; 2) 348 К, в системах АК - ДМСО $(2 ; 3 ; 4)$ и АК - ДМСО хлорбензол (1)

Таким образом установлено, что как в ДМСО, так и в хлорбензоле в интервале температур $\leq 348$ К, АК с достаточно большой скоростью подвергается автоокислению. С целью определения скорости зарождения цепей по реакции автоокисления АК пользовались методом ингибированного окисления. В качестве ингибитора использовали ионол. Опыты показали, что в присутствии ионола при автоокислении системы АК - ДМСО - хлорбензол на кинетических кривых поглощения кислорода не обнаруживаются периоды индукции (табл. 3). Следовательно, ионол не тормозит процесс окисления АК и не влияет на скорость поглошения кислорода.
Таблица 2. Значение скорости поглощения кислорода и периодов индукции при автоокислении $1,84 \cdot 10^{-2}$ моль/л, АК в системе АК - вода - ДМСО. Т $=328 \mathrm{~K}$

\begin{tabular}{c|c|c|c}
\hline$\left[\mathrm{H}_{2} \mathrm{O}\right]$, & {$[\mathrm{DMCO}]$,} \\
моль/л & $\begin{array}{c}V_{O_{2}} \cdot \\
10^{6}, \text { моль/л·с }\end{array}$ & $\tau$, мин \\
\hline 0,00 & 14,04 & 2,90 & 0 \\
1,11 & 13,76 & 2,71 & 0 \\
2,78 & 13,34 & 2,70 & 0 \\
5,56 & 12,64 & $2,14^{*}$ & 2 \\
8,34 & 11,93 & $1,86^{*}$ & 5 \\
27,78 & 7,02 & $1,40^{*}$ & 10 \\
30,57 & 6,32 & $1,25^{*}$ & 24 \\
33,34 & 5,62 & $0,92^{*}$ & 27 \\
44,45 & 2,808 & 0,75 & $\infty$ \\
55,56 & 0,00 & $<0,1$ & $\infty$ \\
\hline
\end{tabular}

*Приведены скорости поглощения кислорода после выхода из периодов индукции

Таблица 3. Влияние концентрации ионола на скорость автоокисления $2,125 \cdot 10^{-2}$ моль/л АК в среде ДМСО $(10$ об.\% $)+$ хлорбензол, $\mathrm{T}=348 \mathrm{~K}$

\begin{tabular}{c|c|c}
\hline $\begin{array}{c}\left.\operatorname{InH}^{\prime}\right] \cdot 10^{4}, \\
\text { моль/л }\end{array}$ & $\begin{array}{c}V_{O_{2}} \cdot 10^{6}, \\
\text { моль/л·с }\end{array}$ & $\tau$, мин \\
\hline 0 & 4,00 & 0 \\
0,927 & 4,10 & 0 \\
1,854 & 4,15 & 0 \\
2,781 & 4,00 & 0 \\
6,180 & 4,20 & 0 \\
\hline
\end{tabular}

\section{Заключение}

На основании этих результатов можно сделать предположение, что автоокисление АК осуществляется не радикально-цепным механизмом.

\section{Список литературы}

1. Meki A.M., Hamed E.A., Ezam Kh.A. Effect of green tea extract and vitamin C on oxidant or antioxidant status of rheumatoid arthritis rat model // Indian Journal of Clinical Biochemistry. 2009. N24(3). Pp. 280-287.

2. Mridula Mahajan, Sukhraj Kaur, Shruti Mahajan, Ravi Kant. Uric acid a better scavenger of free radicals than vitamin C in rheumatoid arthritis // Indian Journal of Clinical Biochemistry. 2009. N24(2). Pp. 205-207.

3. Девис М., Остин Дж., Патридж Д. Витамин С: химия и биохимия. М., 1999. 1976 с.

4. Догарева Н.Г., Богатова О.В. Химия и физика молока. Оренбург, 2004. 137 с.

5. Мельникова Н.Б., Иоффе И.Д. Взаимодействие дигидрокверцетина с ионами металлов в водных растворах их солей и в изотонических медицинских средах // Химия растительного сырья. 2001. №4. С. 25-33.

6. Громовая В.Ф., Некоторые особенности действия аскорбиновой кислоты на окислительно-восстановительные реакции с участием кислорода // Химико-фармацевтический журнал. 1996. №7. С. 305.

7. Weiger W.A., Smith M., Boon H. Advising patients who seek complementary and alternative medical therapies for cancer // Ann Intern Med. 2002. Vol. 137. Pp. 889-903.

8. Чупахина Г.Н. Система аскорбиновой кислоты растений. Калининград, 1997. 120 с.

9. Ефимова И.В. Об особенностях радикально-цепного окисления кумола и аскорбиновой кислоты // Наукові праці ДонНТУ. Серія: Хімія і хімічна технологія. 2012. Вип. 19(199). С. 88-91. 
10. Vickers AJ, Kuo J, Cassileth BR. Unconventional anticancer agents: a systematic review of clinical trials // J. Clin Oncol. 2006. N24(1). Pp. 136-140.

11. Tang Y., Zhou L., Gunnet J.W., Wines P.G., Cryan E.V., Demarest K.T. Enhancement of arachidonic acid signaling pathway by nicotinic acid receptor HM74A // Biochem. Biophys. Res. Commun. 2006. N345(1). Pp. $29-37$.

12. Эмануель Н.М., Денисов Е.Т., Майзус З.К. Цепные реакции окисления углеводородов в жидкой фазе. М., 1965. C. 32.

13. Гордон А., Форд Р. Спутник химика. М., 1976. 514 с.

14. Denisov E.T. Handbook of Antioxidants: Bond dissociation energies, Rate constants, activation energies, and enthalpies of reactions, CRC Press, Boca Raton, New York; Tokyo, 1995. 174 p.

15. Ефремов Е.А., Полина С.А., Струкова Е.Г., Ефремов А.А. Антиоксидантная активность эфирных масел некоторых дикорастущих растений Сибири // Новые достижения в химии и химической технологии растительного сырья: матер. Всероссийской конференции с международным участием. Барнаул, 2012. С. 214-215.

16. Денисова Л.Н., Денисов Е.Т. Образование свободных радикалов в системах $\mathrm{RH}+\mathrm{O}_{2} / /$ Кинетика и катализ. 1969. Т. 10, вып. 6. С. $1245-1248$.

Поступило в редакичию 27 февраля 20142. 
Vardanian R.L. ${ }^{1 *}$, Vardanian L.R. ${ }^{l}$, Airapetian S.A. ${ }^{l}$, Arutiunian L.R. ${ }^{2}$, Arutiunian R.S. ${ }^{2}$ ANTIOXIDANT AND PROOXIDANT ACTION ASCORBYL ACID

${ }^{\text {I} G o r i s ~ S t a t e ~ U n i v e r s i t y, ~ A v a n g a r d, ~ 4, ~ G o r i s ~(A r m e n i a), ~ e-m a i l: ~ v r a z m i k @ ~ r a m b l e r . r u ~}$

${ }^{2}$ Yerevan State University, Aleka Manukiana st., 1, Yerevan 0025 (Armenia), e-mail: syuzanhayrapetyan@ rambler.ru

The antioxidant activity of the ascorbic acid (AA) in the process of the initiated oxidation of the cumene has been studied. It has been established that the antioxidant activity of AA shows itself in relatively low concentrations $\left([\mathrm{AA}] \leq 9,77 \cdot 10^{-3}\right.$ $\mathrm{mol} / \mathrm{l}$ ). The number of radicals terminating on one molecule of AA has also been determined. ( $f$ is the antioxidant capacity). It has been shown that $f<0,6$. In concentrations of $\mathrm{AK}>1 \cdot 10^{-2} \mathrm{~mol} / \mathrm{l}$, the induction periods on the kinetic curves of oxygen absorption vanish. The regularities of the oxidation of AA in the solutions of DMSO, DMSO+water, DMSO+ benzene chloride. It has been shown that water suppresses the rate of the oxidation of AA more whereas chlorobenzene does it 1,14 times more than in DMSO. It has been established that the rate of oxidation of AA in DMSO is described by the equation $V=k[A A] \sqrt{O_{2}}$, где $k=1,44 \cdot 10^{3} \exp (-9440 / R T)$.

Keywords: ascorbic acid, antioxidant activity, prooxydant activity, antioxidant capacity, outo-oxidation, salvation.

\section{References}

1. Meki A.M., Hamed E.A., Ezam Kh.A. Indian Journal of Clinical Biochemistry, 2009, no. 24(3), pp. $280-287$.

2. Mridula Mahajan, Sukhraj Kaur, Shruti Mahajan, Ravi Kant. Indian Journal of Clinical Biochemistry, 2009, no. 24(2), Pp. 205-207.

3. Devis M., Ostin Dzh., Patridzh D. Vitamin S: khimiia i biokhimiia. [Vitamin C: Chemistry and biochemistry]. Moscow, 1999, 1976 p. (in Russ.).

4. Dogareva N.G., Bogatova O.V. Khimiia i fizika moloka. [Chemistry and physics of milk]. Orenburg, 2004, 137 p. (in Russ.).

5. Mel'nikova N.B., Ioffe I.D. Khimiia rastitel'nogo syr'ia, 2001, no. 4, pp. 25-33. (in Russ.).

6. Gromovaia V.F. Khimiko-farmatsevticheskii zhurnal, 1996, no. 7, pp. 305. (in Russ.).

7. Weiger WA, Smith M, Boon H. Ann Intern Med., 2002, vol. 137, pp. 889-903.

8. Chupakhina G.N. Sistema askorbinovoi kisloty rastenii. [System ascorbic acid plants]. Kaliningrad, 1997, 120 p. (in Russ.).

9. Efimova I.V. Naukovi praci DonNTU. Serija: Himija i himichna tehnologija, 2012, no. 19(199), pp. 88-91. (in Russ.).

10. Vickers AJ, Kuo J, Cassileth BR. J. Clin Oncol., 2006, no. 24(1), pp. 136-140.

11. Tang Y., Zhou L., Gunnet J.W., Wines P.G., Cryan E.V., Demarest K.T. Biochem. Biophys. Res. Commun., 2006, no. 345(1), pp. 29-37.

12. Emanuel' N.M., Denisov E.T., Maizus Z.K. Tsepnye reaktsii okisleniia uglevodorodov v zhidkoi faze. [The chain reaction of oxidation of hydrocarbons in zhidoy phase]. Moscow, 1965, pp. 32. (in Russ.).

13. Gordon A., Ford R. Sputnik khimika. [Satellite chemist]. Moscow, 1976, 514 p. (in Russ.).

14. Denisov E.T. Handbook of Antioxidants: Bond dissociation energies, Rate constants, activation energies, and enthalpies of reactions, CRC Press, Boca Raton, New York, Tokyo, 1995, 174 p.

15. Efremov E.A., Polina S.A., Strukova E.G., Efremov A.A. Novye dostizheniia v khimii i khimicheskoi tekhnologii rastitel'nogo syr'ia: mater. vserossiiskoi konferentsii s mezhdunarodnym uchastiem. [Advances in chemistry and chemical technology of vegetable raw materials: materials All-Russian conference with international participation]. Barnaul, 2012, pp. 214-215. (in Russ.).

16. Denisova L.N., Denisov E.T. Kinetika i kataliz, 1969, vol. 10, issue 6, pp. 1245-1248. (in Russ.).

Received February 27, 2014

Revised October 7, 2014

\footnotetext{
* Corresponding author.
} 
